\title{
The Role of the Nurse in Patient Safety: Moving to Level II Relationships
}

\author{
Edgar HS* \\ Professor Emeritus, MIT Sloan School of Management, USA
}

Submission: March 27, 2017; Published: May 15, 2017

*Corresponding author: Edgar HS, Professor Emeritus, MIT Sloan School of Management, USA, Tel: 617-864-7540; Fax: 617-253-2660;

Email: scheine@comcast.net

\section{Short Communication}

In this brief article I would like to point out that nurses in a typical hospital system are not only the key players in facilitating patient safety and patient experience, but are in a uniquely difficult role because of the hierarchy in which they have to operate.

Nurses are the key players because they have the most direct and immediate contact with patients, and are therefore most likely to have critical information about the patient's feelings and physical condition, information which is needed by the other members of the team.

Nurses are in a uniquely difficult role because they have to coordinate their activities with doctors and administrators who are more powerful and have more status in the medical system. At the same time, they have to coordinate with their counterparts as patients get handed off during the hospital stay and with various other members of the team such as pharmacy, physical therapy, patient records, social work and various technicians. In addition they are in the nursing department hierarchy of their own and have to learn how to build effective relationships with their own superiors and subordinates.

I would like to discuss this issue from three perspectives: first the immediate role that nurses play in patient safety by virtue of the information that they have access to about the patient's immediate condition. Second I would like to discuss the difficulty that nurses have in being in the middle of a steep hierarchy and status system, which has implications for patient safety, the quality of patient experience, and their own wellbeing in the system.

\section{The Patient Safety Issue}

Safety issues are almost always the result of lost information or information that was available but was not acted upon. This plays out in several different ways. First, if the nurse is not in good communication with the patient, he or she may not hear or grasp the significance of something the patient is trying to say. I call this "lost information." Second, since the patient will meet other members of the care team at different times of the day, important information about the patient has to be passed off to other members of the team at various times. If the nurse is not in a good relationship with the other members of the team he or she may forget, or withhold, or pass the information on in such a hurried way that it does not really register. Alternatively, the recipient of the information may be hurrying or preoccupied or in some other way not paying attention, and the nurse may not have time to explain. I call this "information not acted upon."

Cases of misdiagnosis, incorrect treatment, giving the wrong medication are almost always the result of such communication problems. The nurse did not hear or pick up on something the patient was trying to say, or did not clearly pass this information on to the doctor or others who will be dealing with the patient, or did not hear clearly what the doctor or another member of the team was trying to tell him or her. It is tempting to then blame one of the members of the team when things go badly and the patient dies, instead of realizing that each member of the team, especially the nurses, are in a difficult coordination role in which good relationships are essential to the transmission and utilization of patient relevant information.

\section{The Nursing Role in the Hierarchy}

If one considers the work of various kinds of organizations, one will quickly discover that healthcare is unique in requiring that the work be done in a coordinated fashion by employees in different technical functions and in different positions within a hierarchy. Nurses are in a particularly difficult position in this regard because they have to operate not only in their own hierarchical nursing unit, but in the hospital's broader hierarchy in which doctors are all-powerful and can dictate to nurses while nurses, and turn, can dictate to other members of the care team.

To illustrate this complexity, I observed the case of a cancer center in a large hospital where the doctors and nurses worked with consultants to identify a process that would make it more 
comfortable for patients who were going to receive chemo or radiological treatment. It was decided that the attending nurse for the treatment should visit the patient the evening before to explain everything and to help ameliorate the inevitable anxiety that the patient would be feeling.

When it was first implemented, the nurse assigned to visit the patient that evening went to patient records to familiarize herself with the case, only to discover that the records were not available because they were being updated in another department. The nurse quested access and was told that this was not possible because it would require a lot of extra work from the records unit which was already overloaded, and the manager of the cancer center who had not been involved in the creation of the new program, was reluctant to order the records department to comply. There was nothing the nurse could do until the whole team was brought together to discuss workflow issues around the new procedure. Getting the team together proved to be difficult and it was decided that the whole procedure of previsits was too complicated and was abandoned. A higher patient quality was sacrificed and there was nothing that the nurse could do about it.

Problems of shortage of staff and consequent work overload are of course always present and have to be dealt with, but I'm trying to highlight that even when there is adequate staffing, the coordination problems of nursing have to be considered if patient safety and quality of patient experience are to be addressed. I have come to believe that the key even in understaffed hospitals is for nurses to become mindful of the kind of relationship that they automatically assume with patients and with others in the hierarchy. To explain this, we need to understand that society offers us two ways to relate to each other.

\section{Level I Transactions to Level II Relationships}

What I am calling a level I transaction is how we relate to others in terms of their occupational or hierarchical role. What I'm calling a level II transaction is how we relate to someone as a total person as with friends. Both of these should be distinguished from a level III interaction which is how we relate to close friends and lovers in a more intimate way.

What I have discovered is that much of our training and the culture on which that training is based proposes that professional relationships such as nurse with patient showed on the whole the level I role related transactions. Applying this to the nursing profession suggests that one should maintain professional distance, not to get to personally involved, not to show favoritism, and in various other ways stay impersonal. The patient is Mr. Smith and the question is "how are we feeling this morning" or, in the middle of the night, "Time for your meds Mr. Smith."

I have also discovered as a teacher and a consultant that when we slip out of this role and become more personal, it is often much more satisfying emotionally and the task we are trying to do is accomplished much better [1,2]. In the nursing scenario this might be as small a change as "good morning Mr. Smith, I see your family brought you some flowers; you are looking perky this morning; how are you feeling?" Or in the middle of the night, "hi Mr. Smith, so sorry to have to interrupt your sleep again, but these meds do have to come every so many hours, so let's get it over with and I hope you can get back to sleep."

Does personalization make a difference? For example, in discussing these two levels of relationship with a group of doctors, the chief medical officer in the group mentioned that in his work on doctor burnout, it was doctors who had personal level II relationships with their patients who were much less burned out because it was so emotionally rewarding and energizing to have those more personal interactions. I have also learned from surgeons that operations go much better if the surgeon takes a little time to personalize the relationships in the OR just before the operation. One example is to use the checklist as an opportunity to give everyone a chance to ask questions, to see if anything is different on that day that needs to be considered, to maintain eye contact during the process, to remind everyone but the goal is to bring this patient back to good health, and to acknowledge the importance of every member of the team, the degree to which they are interdependent, and the importance of anyone speaking up who is observing something that requires attention. The hardest part of this no doubt is for the nurse to speak up when she sees the doctor about to make a mistake. Yet if patient safety is our concern, we have to create climate in the OR that facilitates and encourages any member of the team to speak up.

The implications are profound. I'm suggesting that the reason information is lost, information is not acted upon, or directions and handoffs are misunderstood, and that burnout occurs from too much to do in too little time, is that the group or organization has not figured out how to move to Level II personal relationships with patients and with each other. Being more personal does not take more time, it does not mean becoming friends with patients or colleagues, it does not mean revealing all one's own personal issues, but it does mean a mindset that the other person whether patient or angry surgeon or overworked fellow nurse are individuals trying to do their best and want to be respected as individuals.

\section{Conclusion}

We all know how to be personal, how to be curious about another person, how to use their name rather than their professional title, and how to pay attention to what they say and what other communication signals they are sending. The biggest enemy of being personal is to be totally self preoccupied, to have no room for listening or paying attention. If you are in a caring occupation, it seems to me that professionalism should not involve distancing oneself from one's clients or customers 
or colleagues, but to find a way to be more personal and thereby improve communication and even feel better.

\section{References}

1. Schein EH (2016) Humble consulting: How to provide real help faster. Berrett-Koehler, Oakland, California, USA.

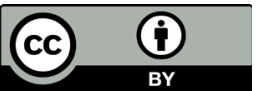

This work is licensed under Creative

Commons Attribution 4.0 License
2. Schein EH (2017) Organizational culture and leadership. (5 $5^{\text {th }}$ edn), Wiley, California, USA.

\section{Your next submission with Juniper Publishers} will reach you the below assets

- Quality Editorial service

- Swift Peer Review

- Reprints availability

- E-prints Service

- Manuscript Podcast for convenient understanding

- Global attainment for your research

- Manuscript accessibility in different formats

( Pdf, E-pub, Full Text, Audio)

- Unceasing customer service

Track the below URL for one-step submission https://juniperpublishers.com/online-submission.php 